\title{
EDUCAÇÕES E(M) BARBÁRIES DO-NO PRESENTE: NEOLIBERALISMO, NEOFUNDAMENTALISMO E NARCISISMOS
}

\author{
Alexandre Luiz Polizel ${ }^{1}$ \\ Moises Alves de Oliveira ${ }^{2}$
}

\begin{abstract}
Resumo: Este manuscrito tem por objetivo traçar considerações acerca das barbáries constituídas pelos atravessamentos neoliberais, neofundamentalistas e de (neo)narcisismo patológico nas educações do-no tempo presente. Tal investigação ancora-se nas bases epistemológicas dos (Pós)Críticas, das Filosofias das Diferenças e dos estudos sobre a (Pós)Modernidade. Este manuscrito toma como base as discursividades do movimento Escola sem Partido presentes em seu sítio eletrônico, a partir de uma hermenêutica do presente de bases em Michel Foucault. Tal movimento analítico leva-nos a instauração de três linhas constitutivas das educações e $(\mathrm{m})$ barbáries do-no contemporâneo: i) a neoliberalização da educação, elaborada a partir de projetos de privatização dos espaços, saberes e subjetividades; ii) o neofundamentalismo na educação, instaurado por regimes de um educar para a moralidade, ressentimento, má consciência e o ideal ascético; iii) a (neo)narcisificação na-da educação, constituído por processos que se intensificaram na pós-modernidade, a superidentificação, a hipertrofia do Eu e o retorno ao totemismo.
\end{abstract}

Palavras-chave: Educações. Filosofia e Educação. Pós-Modernidade. Teorias (pós)Críticas. Barbárie.

\section{EDUCATIONS AND BARBARIANS DO-IN THE PRESENT: NEOLIBERALISM, NEOFUNDAMENTALISM AND NARCISISM}

\begin{abstract}
This manuscript aims to outline considerations about the barbarities constituted by the neoliberal, neofundamentalist crossings and pathological narcissism in the present-day educations. Such research is anchored in the epistemological bases of (Post) Critics, Philosophies of Differences and studies on (Post) Modernity. This manuscript is based on the discourses of the School without Party movement present on its website, from a hermeneutics of the present basis by Michel Foucault. Such an analytical movement leads us to the establishment of three constitutive lines of education and (m) barbaries of the contemporary world: i) the neoliberalization of education, elaborated from projects for the privatization of spaces, knowledge and subjectivities; ii) neofundamentalism in education, established by regimes of educating for morality, resentment, bad conscience and the ascetic ideal; iii) the narcissification in-of-education, constituted by processes that intensified in postmodernity, the overidentification, the hypertrophy of the Self and the return to totemism.
\end{abstract}

Keywords: Educations. Philosophy and Education. Post-Modernity. Critical (post) Theories. Barbarism.

\section{Notas Introdutórias}

Nas esteiras das reflexões acerca das educações na contemporaneidade, somos colocados a refletir as pedagogias que se instauram e se multiplicam. Por pedagogias, compreendemos processos os quais entoam ensinos, educações e constituições de saberes. Para Michel Foucault $(2016 ; 2008 ; 2004)$ tais elaborações de saberes encontram-se ancoradas no acionar de técnicas e tecnologias que dão por substrato o arcabouço para que os enunciados se sustentem enquanto saberes, validando-se enquanto regimes de verdades.

\footnotetext{
${ }^{1}$ Doutorando e Mestre em Ensino de Ciências e Educação Matemática pela Universidade Estadual de Londrina. Professor Colaborador no Departamento de Educação da Universidade Estadual de Londrina. Líder do Grupo de Estudos e Pesquisa em Educações, Narrativas, Culturas e Ciências. E-mail: alexandre_polizel@hotmail.com ${ }^{2}$ Professor no Departamento de Química e no Pós-graduação em Ensino de Ciências e Educação Matemática da Universidade Estadual de Londrina. Doutor em Educação Básica pela Universidade do Vale do Rio dos Sinos. Coordenador do Grupo de Estudos Culturais das Ciências e das educações. Membro do GP Filosofia, educação e condição humana. E-mail: moises@uel.br
} 
Tais técnicas e tecnologias, os artefatos e seus usos, são traçados como linhas (de forças) sob um quadro que dão formas, criam e elaboram algo - os saberes (Nietzsche, 2019). Michel Foucault (2004), conceitua tais linhas nominando enquanto

[...] quatro grupos principais de "tecnologias", cada um deles uma matriz de razão prática: (1) tecnologias de produção, que permitem produzir, transformar ou manipular as coisas; (2) tecnologias dos sistemas de signos, que permitem utilizar signos, sentidos, símbolos ou significação; (3) tecnologias de poder, que determinam a conduta dos indivíduos e os submetem a certos fins ou dominação, objetivando o sujeito; (4) tecnologias de si, que permitem aos indivíduos efetuar, com seus próprios meios ou com a ajuda de outros, um certo número de operações em seus próprios corpos, almas, pensamentos, conduta e modo de ser, de modo a transformá-los com o objetivo de alcançar um certo estado de felicidade, pureza, sabedoria, perfeição ou imortalidade. (Foucault, 2004, p. 323-324)

Assim, as produções das coisas, dos sistemas de signos-símbolos-significados, o poder e os processos de subjetivação encontram-se interligados as pedagogias do contemporâneo. Refleti-las é localizar os percalços pelos quais as educações (des)(re)elaboramse no presente e seus efeitos. Seja nomeando este presente de uma temporalidade neoliberal (Foucault, 2016; 2008), uma era do vazio (Lipovetsky,2005) e/ou enquanto uma pósmodernidade (Lyotard, 2002), o presente demanda que tais reflexões-diagnoses sejam traçadas $^{3}$, visto que esta elabora multiplicidades de pedagogias pungentes e seus modos de subjetivação.

Modos de subjetivação que consistem nos processos pelos quais os sistemas de saberes e suas pedagogias produzem, criam e instauram sujeitos-subjetividades. Tais processos são abertos, contínuos e descontínuos, associada a uma subjetivação voltada as práticas da liberdade e/ou de assujeitamento (Foucault, 2008). Refletir sobre as educações-pedagogias e seus modos de subjetivação na contemporaneidade, convidam a traçar tais reflexões articulando aspectos: i) epistemológicos, ao passo que as elaborações de saberes e discursividades encontrase associada as noções, delimitações e operações das verdades-mentiras (Nietzsche, 2019; Foucault, 2016); ii) aspecto estético, de modo que as sensibilidades e insensibilidades encontram suas faculdades do sentir e dos sentidos enquanto processos apreendidos-formativos (Guattari, 2009; Tiburi, 2016); iii) aspectos éticos, visto que as educações-pedagogias atravessam os jogos de valoração, produção e quadros de referência, ao passo que o corposubjetividade fazem-se educar-educados (Nietzsche, 2019); iv) aspectos políticos, haja vista que os saberes encontram-se intrinsicamente ligados as relações de poder e aos governamentos

\footnotetext{
${ }^{3}$ Compreendemos neste manuscrito que tais diagnoses do tempo presente convergem e ressoam ao que trataremos durante todo o trabalho enquanto educações contemporâneas, educações na contemporaneidade, educações no tempo presente e educação na pós-modernidade.
}

\begin{tabular}{|l|l|l|l|l|l|} 
Qovista Dialectus & Ano 10 & n. 22 & Edição Especial, junho 2021 & p. 175 - 195 \\
\hline
\end{tabular}


que instauram-se a partir de uma formação-subjetivação (Foucault, 2016; 2008; 2004; Guattari, 2009); e v) aspectos desejantes, a proporção que há na educação o agenciar, reprimir e proporcionar que o impulso desejante encontre a representação, objeto de desejo, os canalículos rizomáticos para o investimento libidinal (Guattari, 2009)...

$$
\text { É desta coadunação que compreendemos as educações-pedagogias na }
$$
contemporaneidade, de modo que estas encontram a articulação saberes-poderes-verdadesdesejos e elaboram-se por meio de técnicas e tecnologias que as catalisam a operar: e estas pululam. Vemos que tais articulações multiplicam as reflexões acerca das educações ao passo que os conceitos de identidade e diferenças são trazidos para balizar críticas e a reelaborações acerca destas. Pensar o diverso, cruzar as fronteiras da hegemonia ${ }^{4}$, discutir a ampliação e diversificação das educações, foi o papel das teorizações (pós)críticas: as diferenças olham para a educação, e cobram-na de olhar de volta, e ao olhar torna-se outras (Silva, 2015).

À medida que a educação na contemporaneidade é atravessada pelas (pós)críticas e passa a integrar em suas percepções as diferenças, esta se pluraliza, se ramifica, articulando cada vez com maior intensidade sua fundação ${ }^{5}$ na hibridização epistemológica-estética-éticapolítica-desejante. Contudo, à medida que as diferenças-diversidades borram as fronteiras - e muitas vezes redesenham-nas ${ }^{6}$-, há o exercício de uma reação a tais avanços.

A reação-reatividade, confere Friedrich Nietzsche (2019), consiste no investimento de uma força inversa para estabilizar e conservar os modos operantes vigentes - os regimes de verdade e normatividade em curso - ou revertê-las em busca de uma outra redefinição. Estas buscam neutralizar as políticas de diferenciação e diversificação na educação, pois as diferenças derivam a tradição que desejam conservar. Vê-se que as associações anti-diferença/anti-

\footnotetext{
${ }^{4}$ Compreende-se hegemonia a partir dos escritos e reflexões elaborados por Antonio Gramsci (2006), em que a hegemonia é compreendida não como um sistema estático, como uma imposição de cima de uma superestrutura aos sujeitos que se encontram nas (micro)relações, ou enquanto uma predefinição divina que orienta nossas ações; compreende-se a hegemonia enquanto um campo de disputa, um processo nos quais os limites da vida compreendida como normalizada-normatizada, passível de ser vivida-preservada-legitimada, são disputados tendo sua concepção alargada para com a heterogeneidade ou comprimida para uma homogeneidade. Compreendemos a hegemonia enquanto uma produção que instaura formas de vida e difunde suas discursividades operacionalizadas por meio das educações e suas tecnologias, operando dispositivos de poder e deparando-se com contracondutas de resistência (Foucault, 2016).

${ }^{5}$ Lançou-se uso da concepção de fundação ao considerar que as bases da educação que dialoga com as perspectivas (pós)críticas encontra-se fundamentada na noção de diferença (Silva, 2015).

${ }^{6}$ Compreende-se que a delimitação de novas fronteiras que visam incluir aspectos da diferença no plano educacional, convertendo diferença em identidade, exercem reformulações curriculares inclusivas. Contudo há na noção de identidade uma proximidade com os processos de normatização - incluir é incluir na norma -, do tornar legitimo, do redesenhar fronteiras e redelimita-las. Esta redefinição prescinde que há alguém fora delas, um estrangeiro, não pensado, não imaginado, ou até mesmo eleito enquanto diferente (Foucault, 2016). Não pretendemos com isso deslegitimar a elaboração de políticas públicas que lançam mão da inclusão das 'diferenças', o que desejamos é manter a atenção aos flertes com os regimes de normatização-normalidade, por conhecermos seus sintomas.
}

\begin{tabular}{|c|c|c|c|c|}
\hline Q Rovista Qialectus & Ano 10 & n. 22 & Edição Especial, junho 2021 & p. 175 - 195 \\
\hline
\end{tabular}


diversidade na educação investem na retórica da desarticulação de reflexões sobre as educações na contemporaneidade. Tais anti-movimentos propõe uma educação separada, cindida de uma disjunção epistemológica/estética/ética/política/desejante; tais movimentos reiteram o desejo por uma Escola sem Partido, considerando que estética/ética/política/desejo se encontra separados dos processos educacionais.

Estas associações reativas às diferenciações-diversidades no campo educacional, reiterando-se na propositiva de uma escola-educação supostamente neutra-pura, surgem enquanto um sintoma das educações na contemporaneidade; originam-se ancoradas na exata inversa do que as ciências das educações e suas epistemologias ((pós)críticas) têm proposto para pensar as educações no presente (POLIZEL, 2019a; 2019b). No Brasil, tais agremiações reativas - as diferenças e diversidades - tem encontrado ponto de conexão-identificação no programa Escola sem Partido (EsP).

$\mathrm{Na}$ esteira de compreender as associações reativas enquanto um campo que disputa e elabora educações-pedagogias na contemporaneidade, que representam um anti-movimento (das diferenças e dos estudos tradicionais, críticos e pós-críticos da educação) e disputam os regimes de verdade vigentes no presente, colocamo-nos a indagar: Que linhas constitutivas tramam as malhas de tais pedagogias-educações reativas? Que modos de subjetivação, técnicas e tecnologias encontram-se associadas a instauração, manutenção e repetição destas? Que sintomas estas expressam em termos pedagógico-sociais?

Destas questões, elaboramos um recorte para apresentar neste manuscrito e instigar a reflexões acerca das pedagogias-educações reativas como um sintoma da contemporaneidade. Neste, temos por objetivo traçar considerações acerca das barbáries constituídas pelos atravessamentos neoliberais, neofundamentalistas e de (neo)narcisismo patológico nas educações do-no tempo presente, enquanto efeitos das pedagogias-educações reativas do hoje. Para tal, organizamos nossa diagnose analítica em três eixos: i) a neoliberalização da educação, elaborada a partir de projetos de privatização dos espaços, saberes e subjetividades; ii) o neofundamentalismo na educação, instaurado por regimes de um educar para a moralidade, ressentimento, má consciência e o ideal ascético; iii) a (neo)narcisificação na-da educação, constituído por processos que se intensificaram na pós-modernidade, a superidentificação, a hipertrofia do Eu e o retorno ao totemismo.

\section{Antes... bisturis e suturas para elaborar o diagnóstico}

Para voltar o olhar as pedagogias-educações reativas na contemporaneidade como um sintoma e uma modalidade curricular, ou seja, enquanto uma movimentação que tem por

\begin{tabular}{|c|c|c|c|c|}
\hline Qovista Dialectus & Ano 10 & n. 22 & Edição Especial, junho 2021 & p. $175-195$ \\
\hline
\end{tabular}


intento analisar, organizar e instaurar técnicas-tecnologias que mobilizem modos de subjetivação, voltamos nosso olhar ao Programa Escola sem Partido. O fazemos por compreender que tal programa de educação tomou visibilidade e aglutinou múltiplos seguimentos de pedagogias-educações reativas e as deram corpo e representatividade (Polizel, 2019a; 2019b).

O Programa Escola sem Partido surgiu em setembro de 2003 pela iniciativa privada de seu fundador, Miguel Nagib, ao sentir-se incomodado que o professor de história de suas filhas traçou uma comparação entre as figuras de Che Guevara e São Francisco de Assis. Para Nagib, que é católico, tal comparação foi compreendida enquanto uma santificação da figura de Che Guevara, uma tentativa de agenciar os estudantes a seguir o revolucionário marxista, o que este passou a vislumbrar enquanto uma doutrinação ideológica na escola. Este acontecimento levou o advogado a procurar a direção da escola, associar-se com outros pais e elaborar suas próprias "ferramentas para ajudá-lo nesta disputa" (Penna e Salles, 2017, p. 14) para com professores que discutissem questões associadas, por este, a política. O Programa Escola sem Partido (auto)declara que este é o momento de nascimento ${ }^{7}$.

Esta associação (o EsP) que busca implementar-se enquanto programa educacional, frenteada enquanto um empreendimento pessoal de Miguel Nagib, elabora um conjunto de pautas que se voltam a tratar:

\begin{abstract}
defesa da família e de um certo arcabouço de valores, com ênfase numa orientação patriarcal e hetoronormativa; imposição de uma separação entre assuntos que podem ser abordados na escola e assuntos que só devem ser tratados no espaço privado do lar; desconfiança de instituições e agentes identificadas como promotoras de interesses estatais e governamentais - escolas e professores. (Penna e Salles, 2017, p. 14).
\end{abstract}

Evidencia-se já em seu nascimento que o programa emerge enquanto uma reação as discussões que tocam as diferenças e diversidades delineando o que pode, ou não, ser tratado no campo pedagógico-educacional. Suas bases neste momento ancoram-se sob uma perspectiva anti-marxista, anti-socialista e anti-comunista, eleito como o substrato do que tratarão enquanto o condutor da doutrinação ideológica nos espaços educacionais.

Estas propositivas e investimentos do Escola sem Partido, entretanto só ganham visibilidade em meados de 2014 e 2015, visto as alianças que traça neste percurso e as dinâmicas

${ }^{7}$ Vide, "O professor da minha filha comparou Che Guevara a São Francisco de Assis”. El País Brasil, Política. Paulo, $25 / 6 / 2016$.

Disponível

em: <http://brasil.elpais.com/brasil/2016/06/23/politica/1466654550_367696.html>. Acesso em: 25/05/2021.

\begin{tabular}{|l|c|c|c|c|c|}
\hline Qonista Dialectus & Ano 10 & n. 22 & Edição Especial, junho 2021 & p. 175 - 195 \\
\hline
\end{tabular}


socioculturais do momento levam a produção de um cenário que permite a ascensão do movimento, destacando-se os

\begin{abstract}
três vetos governamentais cedidos em função das pressões políticas: a) a retirada de ações referentes à promoção de direitos sexuais, reprodutivos, laicos, de livre expressão e de reparação contra os crimes da ditadura do Programa Nacional de Direitos Humanos (PNDH) - realizada pelo então Presidente Lula em 2009; b) a proibição no Governo Dilma, em 2011, ao Programa Educacional Brasil Sem Homofobia no ensino fundamental e médio; e, c) a ampla campanha contra a diversidade sexual e cultural nos planos decenais de educação a partir de 2014 que inabilitou a educação para os gêneros e para os pertencimentos sociais como metas educacionais a serem cumpridas no país como um todo. (Carvalho, Polizel e Maio, 2016, p. 196).
\end{abstract}

Soma-se a isto também sua associação com: d) a figura de Olavo de Carvalho, enquanto sujeito que se autointitula enquanto intelectual aliado do programa, passando a fazer divulgações de vídeos e textos, elaborando uma pedagogia-educação nas plataformas virtuais reativa associada ao EsP (Penna e Salles, 2017); e) organizações como Vem Para Rua e Movimento Brasil Livre (MBL), intrinsicamente ligados a perspectiva neoliberal e a tal guia para organização social e economia de mercado; d) Think Thanks ${ }^{8}$, como o Instituto Liberal e o Instituto Millenium; e, e) tornando-se plataforma político-eleitoral nas campanhas pós-2014 por partidos que se autoidentificam enquanto de (centro)(ultra)direita, vinculando-se a disponibilidade de um modelo para propositiva de projeto de Lei para estes - protocolado inicialmente no estado do Rio de Janeiro pelo então Deputado Flávio Bolsonaro.

De tais alianças, o Programa Escola sem Partido encorpa e torna-se representante de tal conglomerado, buscando firmar-se legislativamente em nível Nacional via projetos de lei 867/2015 (Dep. Izalci PSDB/DF), 193/2016 ${ }^{10}$ (Sen. Magno Malta PL/ES ${ }^{11}$ ) e 246/2019 ${ }^{12}$ (Dep. Bia Kicis PSL/DF). Evidencia-se, então, com novidade a tentativa de instaurar pedagogia-

\footnotetext{
${ }^{8}$ Essas associações são "Essas organizações são conhecidas, entre outros propósitos educacionais, pela ênfase na transformação da educação em mercadoria, pela defesa da privatização do sistema público de ensino, pela defesa da implantação do homescholling, "sala de aula invertida" e ensino a distância como estratégias minimizadoras de investimentos e gastos com educação e pelo incentivo à interferência de grupos privados nas escolas" (Furlan e Carvalho, 2020, p. 172). Tais organizações recebem financiamento e encontram-se distribuídas internacionalmente, investindo para um mote neoliberal para pensar as educações formais e não formais, produzindo um modo de subjetivação articulado a perspectiva neoliberal.

9 O referido projeto de lei encontra-se disponível em: <https://www.camara.leg.br/proposicoesWeb/fichadetramitacao?idProposicao=1050668>. Acesso em 05/05/2021 ${ }^{10} \mathrm{O}$ referido projeto de lei encontra-se disponível em: <https://www25.senado.leg.br/web/atividade/materias//materia/125666>. Acesso em 05/05/2021

${ }^{11}$ Ressalta-se que o projeto de lei protocolado pelo Senador Magno Malta (PL/ES) de número 193/2016, encontrava resistências para ser aprovado no senado. Como este seria o primeiro projeto a ser votado, e caso recusado apresentaria problemas para a propositiva que tramitava na Câmara dos Deputados (867/2015), foi retirado de pauta pelo próprio autor no dia 21/11/2017.

12 O referido projeto de lei encontra-se disponível em: <https://www.camara.leg.br/proposicoesWeb/prop_mostrarintegra?codteor=1707037\&filename=PL+246/2019>. Acesso em 05/05/2021
} 
educação reativa pelas vias legislativas, tentativa esta associada a busca de difusão para o convencimento social da importância de tal programa educacional-social ${ }^{13}$.

Esta visibilidade e disputa jurídico-legislativa balizada pelo EsP nos instiga a voltar o olhar para o mesmo enquanto um campo de análise para compreender os efeitos das pedagogias-educações reativas do hoje, seus substratos e modos de subjetivação (produtores e produzidos nos entornos do EsP). Para tal buscamos analisar o projeto de Lei 246/2019 (Dep. Bia Kicis PSL/DF) ${ }^{14}$, bem como buscar ruídos que nos permitam traçar reflexões no sítio eletrônico do Programa Escola sem Partido ${ }^{15}$.

Para instrumentalizar nossos olhares ancoramo-nos nas bases epistemológicas das teorizações (Pós)Críticas, das Filosofias das Diferenças e dos estudos sobre a (Pós)Modernidade. Deste olhar compreendemos as analíticas enquanto processos que nos permitem elaborar tramites de cortes e conexões, elaborar interpretativas e narrativas guiadas por chaves conceituais, buscando não esgotar as discussões, mas colocá-las em pauta. Michel Foucault $(2016 ; 2004)$ compreende tais empreendimentos enquanto processos de críticas, em que colocam sob o olhar reflexão acerca de questões pulsantes e urgentes. É no investimento da crítica que nos indagamos sobre as condições e efeitos-sintomas de algo, colocando-o sob o julto da razão. É pela crítica que se faz possível uma hermenêutica do presente.

Para Friedrich Nietzsche (2019), quando analisamos algo, colocamos sob nosso olhar, fazemos uso de conceitos para elaborar, criar e nomear algo que nos escapa a linguagem. Como em um processo criativo damos nome ao que identificamos operando. A crítica é o que nos move ao percorrer os rastros das operações e suas ações, a crítica é o que torna possível nomeá-la. Nossa bussola para seguir as linhas de força, as técnicas-tecnologias, os modos de subjetivação das pedagogias-educações reativas no presente - a partir do olhar para o Programa Escola sem Partido - são os conceitos. Tais conceitos nos são emprestados pelas teorizações (Pós)Críticas, das Filosofias das Diferenças e dos estudos sobre a (Pós)Modernidade, sendo acionados pelo nosso contato com o projeto de Lei 246/2019 e pelo site do EsP. São três os empréstimos que fazemos-evidenciamos e que nos permitem nomear os modos de subjetivação

\footnotetext{
13 Demarca-se aqui que tal propositiva não ocorre apenas no Brasil, é um fenômeno internacional que pode ser percebido na América Latina com o (anti)movimento Con Mis Hijos No Te Metas, na Argentina, Bolívia, Paraguai e Peru. Movimentos similares têm pululado também nos Estados Unidos, Espanha, França e União Européia.

${ }^{14} \mathrm{Tal}$ opção foi realizada haja visto que os projetos foram realizados sob um mesmo modelo disponibilizado no site do EsP, sendo então similares. Contudo o modelo elaborado pela Dep. Bia Kicis PSL/DF, conhecido como a versão 2.0 do projeto, buscava incluir como direito legal a filmagem dos professores em seu trabalho pelos estudantes, mesmo que sem o consentimento do docente.

15 O sítio eletrônico do Programa Escola sem Partido encontra-se disponível em: <https://www.escolasempartido.org/>. Acesso em 05/05/2021
}

\begin{tabular}{|l|l|l|l|l|}
\hline Q Rovista Qialectus & Ano 10 & n. 22 & Edição Especial, junho 2021 & p. 175 - 195 \\
\hline
\end{tabular}


das pedagogias-educações reativas do presente: neoliberalização da educação, neofundamentalismo na educação e, (neo)narcisificação na-da educação.

\section{Neoliberalização da Educação}

Não existe essa coisa de sociedade, o que há e sempre haverá são indivíduos - Margareth Thatcher

A sentença de Margareth Thatcher publicada em 1993 na obra The Dowing Street Years, representa a organização de uma temporalidade: o neoliberalismo. A representação é dada ao passo que os sujeitos, produtos de uma relação com o Outro e o coletivo, são desagregados em indivíduos. Esta derivação inaugura um outro regime de racionalidade, guiado pela lógica do mercado, a desregulamentação dos regimes de seguridade e do bem-estar social, e de um modo de subjetivação assujeitadora que torna o sujeito empresário de si (Foucault, 2008).

Pierre Dardot e Christian Laval (2016), ressaltam que

O neoliberalismo, antes de ser uma ideologia ou uma política econômica, é em primeiro lugar e fundamentalmente uma racionalidade e, como tal, tende a estruturar e organizar não apenas a ação dos governantes, mas até a própria conduta dos governados. A racionalidade neoliberal tem como característica principal a generalização da concorrência como norma de conduta e da empresa como modelo de subjetivação. (Dardot e Laval, 2016, p. 17)

Esta forma outra de organização social, suas pedagogias-educações e subjetivações, aliam-se a um ethos ancorado no individualismo, hiperprodutivismo, concorrência e do tomar o Outro enquanto um possível adversário. O indivíduo - e não mais sujeito, se ainda assim quisermos tomá-lo enquanto sujeito precisaremos demarcá-lo enquanto sujeito neoliberal - é estimulado a uma produção ativa e continua, explora os recursos que tem e a si mesmo para garantir o desempenho máximo e o máximo lucro. Esta máxima exploração-desempenho-lucro ancora-se nas noções de privatização, liberdade, mercado e propriedade (Dardot e Laval, 2016).

Ao voltarmos os olhares para o Programa Escola sem Partido, evidenciamos que o programa se embasa nestes quatro marcos constitutivos de um arcabouço neoliberal: i) a privatização do que confere ao campo do público; ii) o deslocamento da noção de liberdade em suas condicionantes; iii) a propositiva de uma educação voltada ao mercado; e, iv) a subjetividade tornada propriedade de um sócio-investidor.

Primeiro marco constitutivo: a privatização do que confere ao campo do público. Vê-se que o Programa EsP traz em sua retórica a visão de que as propositivas pedagógicoeducacionais dever-se-iam estar interligadas as concepções privadas das famílias (Furlan e 
Carvalho, 2020). Para tal buscam firmar-se em um movimento dual: investindo na deslegitimação, depredação e acusação da educação púbica com o intuito de depreciá-la, operando por uma retórica-educação reativa-negativa; e, em movimento inverso instaura a propositiva de uma educação orientada pelas moralidades-religiosidades dos pais como neutra, imparcial e não doutrinária.

Evidencia-se que tais aspectos são dispostos logo no início da 'Justificativa' do projeto de lei 246/2019 (Brasil, 2019), ao afirmar que os "professores e autores de livros didáticos vêm-se utilizando de suas aulas e de suas obras para tentar obter a adesão dos estudantes a determinadas correntes políticas e ideológicas” (Brasil, 2019, p. 3). Tal afirmação é realizada pela própria percepção privada da Dep. Bia Kicis (PSL/DF) e dos proponentes do programa EsP, haja visto a inexistência de quaisquer trabalhos científicos que substancializem tal pontuação em cenário nacional ou internacional.

A 'justificativa' do projeto segue indicando que o mesmo tem por intuito garantir o não uso de "técnicas de manipulação psicológica [...] dogmatismo [...] e proselitismo" (Brasil, 2019, p.1), buscando então de modo "urgente adotar medidas eficazes para prevenir a prática de doutrinação política e ideológica" (Brasil, 2019, p.4). Se voltarmos o olhar para o sítio eletrônico do Programa EsP a retórica é mantida e reiterada, como evidencia-se nos textos "Ataque ao EsP revela falsos amigos das crianças e dos adolescentes"16, "Alienação parental: uma prática também cometida pelos professores"17, "Depoimentos"18, entre outros... Tanto no projeto de Lei quanto nos textos disponíveis no site do Programa EsP, evidencia-se que o discurso do EsP busca justificar-se e sustentar-se a partir da noção de que a figura do professoreducar encontra-se interligada a possível perturbação da ordem, a fonte de todo mal, sendo estes possíveis violadores dos estudantes e da moral vigente (Carvalho, Polizel e Maio, 2016; Polizel, 2019).

Os professores manifestariam este mal ao tratarem temas que vertem o encontro para com as diferenças e diversidades. Discussões sobre gênero ${ }^{19}$, críticas ao capitalismo e ao

\footnotetext{
16 Texto encontra-se disponível em: <https://escolasempartido.org/blog/ataque-ao-esp-revela-falsos-amigos-dascriancas-e-adolescentes/>. Acesso em 05/05/2021

${ }^{17}$ Texto encontra-se disponível em: <https://escolasempartido.org/blog/alienacao-parental-uma-pratica-cometidatambem-por-professores/>. Acesso em 05/05/2021

${ }^{18}$ Os depoimentos encontram-se disponíveis em: 〈https://escolasempartido.org/?s=depoimentos〉. Acesso em $05 / 05 / 2021$

${ }^{19}$ Vide texto "MP processa colégio particular em BH por martelar ideologia de gênero na cabeça dos alunos", disponível em: <https://escolasempartido.org/blog/mp-processa-colegio-particular-de-bh-por-martelar-ideologiade-genero-na-cabeca-dos-alunos/>. Acesso em 05/05/2021
}

\begin{tabular}{|l|l|l|l|l|l|} 
Qovista Dialectus & Ano 10 & n. 22 & Edição Especial, junho 2021 & p. 175 - 195 \\
\hline
\end{tabular}


status quo ${ }^{20}$, são compreendidos como a falência das pedagogias-educações e uma violação aos direitos dos pais de exercerem sua/a educação moral-religiosa sobre seus filhos (Brasil, 2019). A ideia promovida pelo Programa EsP faz-se ao investir na deslegitimação, depreciação e acusação da educação pública com o intuito de esgotá-la.

A propositiva do Programa EsP é reorientar e redefinir as pedagogias-educações de modo reativo, centrando então no reestabelecimento das funções e deveres dos professores que deveriam ser vigiados constantemente, temidos e punidos enquanto possível fonte de todo mal (Carvalho, Polizel e Maio, 2016) -, ao estabelecer em seu art. 4 que os docentes:

I - não se aproveitará da audiência cativa dos alunos para promover os seus próprios interesses, opiniões, concepções ou preferências ideológicas, religiosas, morais, políticas e partidárias;

II - não favorecerá nem prejudicará ou constrangerá os alunos em razão de suas convicções políticas, ideológicas, morais ou religiosas, ou da falta delas;

III - não fará propaganda político-partidária em sala de aula nem incitará seus alunos a participar de manifestações, atos públicos e passeatas;

IV - ao tratar de questões políticas, socioculturais e econômicas, apresentará aos alunos, de forma justa, as principais versões, teorias, opiniões e perspectivas concorrentes a respeito da matéria;

$\mathrm{V}$ - respeitará o direito dos pais dos alunos a que seus filhos recebam a educação religiosa e moral que esteja de acordo com as suas próprias convicções;

VI - não permitirá que os direitos assegurados nos itens anteriores sejam violados pela ação de estudantes ou de terceiros, dentro da sala de aula (Brasil, 2019, p. 3, grifos nossos)

Vê-se que dos novos deveres propostos/estabelecidos, nos parágrafos I, II, III e VI tratam (d)o professor em uma negatividade, daquilo que este não pode e não deve fazer; em contraponto os únicos itens propositivos são II e III, e refletem a trabalhar os conteúdos de modo a não tocarem a educação religiosa e moral dos pais. As linhas de subjetivação trazidas aqui enfocam em tratar o público pelo plano do esvaziamento, do perigo, do negativo (ao qual são reativos); enquanto o privado deve passar a ser considerado como guia dos conteúdos e discussões a ser levadas para os espaços escolares. Tal estratégia de esvaziamento do plano público e da validação de saberes a partir de uma óptica privada encontra-se entranhada na privatização (e ao fim) do espaço público (Dardot e Laval, 2016); bem como na privatização das subjetividades haja visto que os critérios de validação coletivos pelas ciências e educações deixam de ser considerados para guiar as trajetórias formativas, dando espaço ao plano do privado para validação pedagógico-educacional (Polizel, 2019).

Evidencia-se neste sentido a inversão acionada pela reatividade (Nietzsche, 2019; Freud, 2011; 1996), ao passo que a educação norteada pelo interesse do público, do coletivo,

20 Vide a exemplo o texto "Paulo Freire e a Educação Bancária Ideologizada", disponível em: <https://escolasempartido.org/blog/paulo-freire-e-a-educacao-bancaria-ideologizada/>. Acesso em 05/05/2021

\begin{tabular}{|l|l|l|l|l|l|} 
Q Rovista ¿ialectus & Ano 10 & n. 22 & Edição Especial, junho 2021 & p. 175 - 195 \\
\hline
\end{tabular}


do historicamente cumulado, da heterogeneidade-diferença-diversidade é visto enquanto uma ação doutrinária; e, a orientação privada da educação, da moralidade dos pais, da homogeneidade, é vista como neutra, imparcial, como direito a ser resguardado. Tal inversão privatiza o público, ao passo que o orienta pelos interesses privados.

$\mathrm{Na}$ tentativa de substancializar esta inversão reativa, o projeto de Lei 246/2019 aciona apenas dois documentos oficiais: i) Constituição Federal de 1988, em seu disposto no "Art. $5^{\circ}$ VI. é inviolável a liberdade de consciência e de crença, sendo assegurado o livre exercício dos cultos religiosos e garantida, na forma da lei, a proteção aos locais de culto e a suas liturgias" e Art. 19 "I. I - estabelecer cultos religiosos ou igrejas, subvencioná-los, embaraçar-lhes o funcionamento ou manter com eles ou seus representantes relações de dependência ou aliança, ressalvada, na forma da lei, a colaboração de interesse público (Brasil, 1988, s/p/); e ii) Convenção Americana de Direitos Humanos "Convenção Americana sobre Direitos Humanos, vigente no Brasil, já assegura aos pais “o direito a que seus filhos ou pupilos recebam a educação religiosa e moral que esteja acorde com suas próprias convicções.” (Brasil, 2019, p.5). Ressalta-se que essa tentativa de substanciar o Programa EsP lança mão de citação de direitos relacionados a vida privada, sendo que a educação consiste em um direito relacionado a vida pública - indicação evidenciada nos mesmos documentos citados.

Percebe-se neste sentido que há um investimento do Programa Escola sem Partido em privatizar o campo do público e os modos de subjetivação que emergem nestes de modo heterogêneo, diverso e diferenciativo - tornando-os homogêneos, iguais e normatizados.

Segundo marco constitutivo: o deslocamento da noção de liberdade em suas condicionantes. Vê-se que a retórica neoliberal se encontra alinhada a ruptura de limites, regulações, fronteiras para expansão do capital. Na racionalidade neoliberal entoa-se a noção de liberdade, esta passa a ser disputadas por outras vias que não a do liberalismo clássico. Esta rompe com a noção de igualdade para o bem-estar social, a igualdade que vigora nesta é a igualdade para a competição (Dardot e Laval, 2016).

A liberdade é colocada em cena enquanto liberdade de governamento, o qual o sujeito neoliberal deverá atuar, se autogerir, autoexplorar, antoempreender (Foucault, 2016; 2008). A lógica da liberdade é fazer mais, gozar mais, produzir mais, trabalhar mais, estudar mais... Alinhado a retórica neoliberal o Programa Escola sem Partido constitui-se sob uma disputa pela noção de liberdade, contudo este torce a noção de liberdade para direcioná-la por outras vias. 
Como no marco anterior, há uma movimentação dual no entorno das liberdades: um movimento de negativação no que toca a liberdade de ensinar, aprender e pluralizar ideias, e um movimento de positivação da liberdade de consciência e crença-moral. Sãos os professores e pais colocados novamente na posição da negatividade e positividade, respectivamente.

É perceptível no projeto de lei que ao falar sobre liberdade de ensinar, ressalva que "A liberdade de ensinar, obviamente, não confere ao professor o direito de se aproveitar do seu cargo e da audiência cativa dos alunos" e "Liberdade de ensinar - assegurada pelo art. 206, II, da Constituição Federal - não se confunde com liberdade de expressão; não existe liberdade de expressão no exercício estrito da atividade docente" (Brasil, 2019, p. 4, grifos nossos). O investimento é restringir a ação do plano público, da atividade docente voltada a ampliação das reflexões, da discussão, das críticas, da diferenciação como processo formativo e constitutivo dos sujeitos. A restrição do público é acionada para retirá-lo de cena dando espaço para a operacionalização privada.

No contrapelo, ao tratar das liberdades do campo privado é sempre ressaltado que "A liberdade de consciência e de crença - assegurada pelo art. 5, VI, da Constituição Federal - compreende o direito do estudante", "liberdade política do estudante", "liberdades fundamentais dos estudantes e dos seus pais [...] de consciência e crença" (Brasil, 2019, p. 34). A propulsão é que os direitos do campo do privado sejam assegurados e invadam o campo do público, em um movimento alinhado a privatização, mas para além deste enquanto um reenquadre do compreendido enquanto liberdade.

Vê-se que o neoliberalismo se constitui invertendo a noção da liberdade antes garantidas pelos regimes de seguridade social e bem-estar. No neoliberalismo as liberdades são recondicionadas e tratadas enquanto a garantir do agir privado e, do agir privado guiado por interesses e lógicas econômicas-mercadológica (Foucault, 2008).

A liberdade de ensinar garantiria que o encontro da lógica neoliberal: com as discussões sobre o limite dos interesses pessoais e das lógicas econômicas frente ao plano público, a falta de liberdade caso não existam garantias básicas para todas e todos (como saúde, segurança, educação e habitação), bem como efeitos das políticas neoliberais no mundo. Devido a isso esta é restringida, acusada de ferir a liberdade de consciência e confundida-associada por ignorância ou má fé - com liberdade de expressão (Polizel, 2019a; 2019b). Faz-se tal inversão com o intuito de recondicionar a noção de liberdade, do plano público para o plano do priva(tiza)do-econômico. 
Terceiro marco constitutivo: a propositiva de uma educação voltada ao mercado. Ao redesenhar os limites e possibilidades do campo da educação, no escopo do projeto de lei temos a impressão de que a preocupação é com discussões educativas por fios (pós)críticos que possam colocar a moralidade apreendida com os pais em dúvida ou questionamento - o Programa Escola sem Partido considera tal fato como um ato de 'doutrinação ideológica'. Contudo no olhar ao projeto não nos fica claro como os investimentos da privatização do campo público, da subjetividade e o recondicionamento da noção de liberdade encontrava-se interligado ao objetivo da propositiva da educação.

A esta questão, encontramos traços de seu intento no sítio eletrônico do Programa EsP. Logo nos 'artigos' de opinião que se encontram em destaque na página principal do programa evidencia-se a frase "no afã de envenenar os alunos contra o capitalismo" 21 , tal lógica se estende ao passo que a principal via de ataque do EsP em seu sitio eletrônico diz sobre as perspectivas (neo)marxistas, socialistas e comunistas, versando a investida ostensiva a questões de vestibulares, conteúdos trabalhados, posturas docentes e produções intelectuais - na verdade, todas as questões escolares que versam sobre diferença e diversidade são compreendidas como um tipo de 'marxismo cultural'.

Identifica-se que reatividades do EsP dão-se para com as diferenças-diversificações no campo das educações, buscando reiterar o direito de moralidade dos pais. Estas reatividades vão além da especulação e elaboram uma defesa da tradição da organização capital, e propõe um papel da escola voltada ao mercado de trabalho (Carvalho, Polizel e Maio, 2016). A lógica é dar condições para a produção e, uma educação alinhada ao impulsionamento da economia (Dardot e Laval, 2016).

Tal investimento constitutivo assenta as políticas neoliberais tal como descrito por Michel Foucault (2008), de modo que a preparação focada no trabalho e na produção planificaria a possibilidade dos sujeitos se autogovernarem, autoexplorarem e hiperproduzirem - terem desenvolvimento e lucros máximos. Neste sentido a escola enquanto âmbito da produção da disciplina não é esvaziada (Foucault, 2016), mas avança-se para além das disciplinas de modo a garantir que os sujeitos interiorizem as instituições e se autogovernem a partir de um próprio olhar voltado a si mesmo e de uma hiperestimulação produtiva (Guattari, 2009).

21 Vide no texto disponível em: <http://escolasempartido.org/blog/o-vale-tudo-da-doutrinacao/>. Acesso em $05 / 05 / 2021$

\begin{tabular}{|l|l|l|l|l|}
\hline QRovista Dialectus & Ano 10 & n. 22 & Edição Especial, junho 2021 & p. 175 - 195 \\
\hline
\end{tabular}


Os processos de reflexão, as críticas, colocar os próprios modos de produção em questionamentos - como fazem reflexões sobre os socialismos, agroecologias, diversidadesdiferenças constitutivas e produtivas, entre outras - desacelera a produção acelerada do pensamento, lança tempo para o pensar e ruminar as possibilidades (Nietzsche, 2019; Lipovetsky, 2005). Neste sentido, voltar a escola a lógica do mercado, não é uma inocência, é a constituição de um arcabouço que estruture a autoexploração-autogoverno-maximização.

A propositiva do Programa EsP consiste, assim, em: uma escola voltada as técnicastecnologias e subjetividades ao-do mercado, a consciência fica a cargo das privatizações familiares-religiosas - fazendo uso, inclusive, do campo escolar por meio das intervenções das famílias.

Quarto marco constitutivo: a subjetividade tornada propriedade de um sócioinvestidor. Perceptamos que a lógica neoliberal encontra um quarto ponto de sustentaçãoconstituição ao passo que localiza os estudantes. Os estudantes são tomados enquanto a parte mais frágil do elo da relação, são os sujeitos de uma "audiência cativa" (Brasil, 2019, p.1) que podem ser aproveitados, violados e doutrinados pelos docentes. Ao estudante retoma-se a posição de aluno, em sua concepção mais primária: o composto pela partícula 'a', prefixo de negação que simboliza aquele que não possui algo, e 'luno/lumini', a iluminação-consciência.

O aluno para o Programa EsP tem sua consciência apenas pelo intermédio da consciência-moralidade dos pais e responsáveis, sendo uma extensão destes. Como o aluno não tem consciência e autonomia própria ${ }^{22}$, o balizador da doutrinação é a violação, mudança ou questionamento sobre a consciência-moralidade dos familiares, que possuem o "direito [...] de que seus filhos recebam a educação religiosa e moral que esteja de acordo com as suas próprias convicções" (Brasil, 2019, p.1).

Se voltarmos o olhar para uma lógica antropológica característica do período medievo, perceberemos que há uma noção de continuidade-prolongamento dos pais no investimento que fazem em seus filhos; se voltarmos o olhar aos processos de subjetivação, vemos que os filhos são compreendidos aí enquanto uma propriedade a não ser violada. $\mathrm{O}$ filho é tomado enquanto propriedade, um filho-propriedade; a escola cabe a tutela da propriedade na ausência dos pais. Vê-se que tal montante dá subsídio a uma racionalidade neoliberal, ao passo que até mesmo o Outro-individuo toma sentido-significado na lógica do mercado (Polizel,

${ }^{22}$ Ressalta-se que a concepção dos sujeitos enquanto seres da consciência, liberdade, responsabilidade e criação é a base para pensar as educações pelas-para as diferenças a partir de ópticas (pós)críticas (Silva, 2015).

\begin{tabular}{|c|c|c|c|c|}
\hline Qevista Dialectus & Ano 10 & n. 22 & Edição Especial, junho 2021 & p. $175-195$ \\
\hline
\end{tabular}


2019a). O Outro-individuo torna-se propriedade pois os pais enquanto empresários investem nestes, é seu sócio-investidor.

A neoliberalização da educação faz-se como base e empreendimento do Programa EsP, ao passo que faz operar i) a privatização do que confere ao campo do público; ii) o deslocamento da noção de liberdade em suas condicionantes; iii) a propositiva de uma educação voltada ao mercado; e, iv) a subjetividade tornada propriedade de um sócio-investidor.

\section{Neofundamentalismo na Educação}

Percorremos até aqui um caminho que nos permitiu vislumbrar um conglomerado de fios condutores que articulam a neoliberalização da educação como uma das bases para os modos de subjetivação propostos-programados pelo EsP. Todavia, há outros fios condutores que se encontram nesta esteira, dentre eles o neofumdamentalismo na educação.

Evidencia-se que as bases do movimento buscam orientar sua noção de constitucionalidade a partir do "direito dos pais dos alunos a que seus filhos recebam a educação religiosa e moral que esteja de acordo com as suas próprias convicções” (Brasil, 2019, p.1); buscando entoar tal diretiva no aliar-se a aparatos descritos na Convenção Interamericana de Direitos Humanos - apenas no que toca o direito dos pais a educação moral e religiosa de seus filhos - e no art. 5o e 19a da Constituição Federal de 1988 (Brasil, 1988), de igual teor. Vislumbra-se que a própria origem do movimento toca um catolicismo, de Miguel Nagib, que vê na comparação de São Francisco de Assis e Che Guevara uma heresia. No sítio eletrônico multiplicam-se textos e depoimentos, a exemplo "Ladainha sobre diferentes modelos de família esconde ataque a moralidade cristã ${ }^{\prime 23}$, que se ancoram na noção de que há uma tradição referente a subjetividade cristã e capitalista que deve ser preservada, conservando as noções de normalidade-moralidade vigente. Somado a isso o próprio site do Programa EsP tem por categoria aglutinadora de textos em seu blog intitulada "Educação Moral e Religiosa"24.

Tais aspectos evidenciam que outro conglomerado de linhas de força que sustentam o Programa EsP e seu plano de subjetivação encontra-se atrelado ao operador do neofundamentalismo na educação. Toma-se este mecanismo em dois movimentos: i) as bases de um neofundamentalismo que se intensifica-inverte; e ii) as linhas de subjetivação da moralidade neofundamentalista penetrando o ressentimento, a má consciência e o ideal ascético como cruzeiro do sul da pedagogia-educação reativa.

23 Texto encontra-se disponível em: <http://escolasempartido.org/blog/ladainha-sobre-diferentes-modelos-defamilia-esconde-ataque-a-moralidade-crista/ $>$. Acesso em 05/05/2021

24 Este aglutinador encontra-se disponível em: <http://escolasempartido.org/blog/category/educacao-moral-ereligiosa/>. Acesso em 05/05/2021

\begin{tabular}{|l|l|l|l|l|}
\hline Q Rovista Dialectus & Ano 10 & n. 22 & Edição Especial, junho 2021 & p. 175 - 195 \\
\hline
\end{tabular}


No que toca as bases de um neofundamentalismo que se intensifica-inverte a vemos em proposição-funcionamento de modo que o EsP busca instaurar a escola como um espaço fechado. A educação é segmentada e separa-se de seus aparatos epistemológicos, políticos, estéticos, éticos e desejantes; a educação é separada pois o espitemológico-político-estéticoético-desejante representa um risco a moralidade-religiosidade, lidos como não neutros, possivelmente doutrinários. Fecha-se os espaços para "impedir que crianças e jovens experimentem o mundo, com medo do terror e da violência" (Gallo, 2009, p. 20). A delimitação deste espaço fechado é evitar o possível encontro-toque desestabilizador para com a moralidade-religiosidade dos pais; evitar um possível conteúdo estrangeiro que pode colocar as fronteiras da moralidade-religiosidade em questionamento e, a possibilidade de os estudantes desejarem o encontro com esse saber-estrangeiro, saber-outro (Guattari, 2009; Gallo, 2009).

Alfredo Veiga-Neto (2009), ajuda-nos a compreender os (neo)fundamentalismo e sua estruturação ao pontuar que o fundamentalismo: i) demarca princípios que seriam considerados fundamentais para uma moral-religiosidade, elabora um cenário do comum; e ii) que os indivíduos mantenham uma postura mental-social ancorada na noção de obediência a princípios fundamentais, um dogmatismo-ortodoxia. Na esteira da sustentação da educação moral-religiosa, é identificado que o fundamentalismo oferece seus arcabouços ao Programa EsP, contudo sua própria engenharia converte-se em neofundamentalista: a linguagem do comum que o fundamento propunha é torcido e 'renovado' em uma linguagem da normahegemonia neoliberal-cristã; a noção de obediência aos princípios morais-religiosos de modo dogmático-ortodoxo é flexibilizada, ao passo que o saber-poder operado pode ser distinto se for mais rentável e produtivo (Foucault, 2016; 2008).

Ainda é possível ressaltar uma terceira base de largada para o Programa EsP neofundamentalizar a educação: suas próprias alianças constitutivo-sociais. Vê-se, que o EsP se flexibilizou e transformou-se para fazer diferentes elos e encorpar-se: o anti-marxismo/antisocialismo tornou-se anti-Gênero, anti-Movimento Sem Terra, anti-Questões étnicas-raciais, anti... (Carvalho, Polizel e Maio, 2016; Polizel, 2019). Tal flexibilidade levou-o a fazer alianças políticas com a Bancada Evangélica do Brasil e partidos políticos que se nomeavam como conservadores e/ou neoliberais - apesar do jogo de incoerências em tais autoidentificações. Tais fatores destituem o Programa EsP de uma noção fundamentalista, pois o fundamentalismo segue seu fundamento com vias de obedecer de modo dogmático-ortodoxo a um regime de verdade (Gallo, 2009); a flexibilização de suas bases com intuito de creditação política- 
econômica, leva a revisar seus fundamentos e modificá-los para atender as demandas dos novos associados, estabelecendo um novo fundamento, um neo-fundamento.

Para Marcia Tiburi (2016) estas modificações que seguem uma lógica do mercado - modificar para atender, estabelecer, lucrar e ser mais consumido - é característica de um neofundamentalismo alinhado as políticas neoliberais. Esta ação confere ao Programa EsP não a busca de uma base moral-religiosa, mas o uso de um discurso moral-religioso para que este torne-se estatuto de verdade a ser colocado para todas e todos. Sua conceção é neofundamentalista pois não busca o fundamento da moral-religiosidade de modo dogmáticoortodoxo, mas sim faz uso do fundamento moral-religioso para situar-se políticaeconomicamente e empreender seu programa educacional-social. Enquanto no fundamentalismo há vontade de salvação guiada pelo medo e obediência, no neofundamentalismo há uso do medo e da obediência orientados pela-para vontade de poder.

Esta vontade de poder orienta as linhas de subjetivação da moralidade neofundamentalista por uma lógica negativa-reativa (Silva, 2009), penetrando o ressentimento, a má consciência e o ideal ascético como cruzeiro do sul da pedagogia-educação reativa na contemporaneidade (Nietzsche, 2019; Polizel, 2019b).

Identificamos tal movimentação ao passo que para Friedrich Nietzsche (2019) a moralidade se coloca e difunde em três segmentações-cisões da-na subjetividade: i) impulsionar do ressentimento, do processo subjetivo em que o Outro-sujeito está sempre disposto a te perverter, desorientar, te retirar do caminho e te violar - esta linha elabora o Outro-sujeito como fonte de todo mal e um culpado o qual devemos estar atentos para manter a moralidadereligiosidade em funcionamento -, no Programa EsP o professor-educador é colocado nesta posição estimulando a vigília para com este; ii) o sentimento de que se pode ter sido doutrinado, operar por uma falsa consciência, coloca o aluno-indivíduo indagar-se continuamente se não foi mal instruído, estimulando uma vigília constante de si e a sensação de culpa-medo como mote desta - os estudantes e pais são colocados nesta posição de má consciência, encontrandose sempre em vigília-policiamento para consigo mesmo; iii) tanto o ressentimento quanto a má consciência são orientados por um ideal ascético, materializado na figura do pai-responsávellei enquanto uma extensão de um modelo social-subjetivo de moralidade neoliberal e neofundamentalista cristã - este ideal encontra-se figurado na propositiva do Programa EsP, devendo este ser seguido e orientar as educações enquanto um estatuto de verdade. 
Tais alinhaves do educar para a moralidade-religiosidade a partir do ressentimento, má consciência e o ideal ascético, dão substrato para os usos neofundamentalistas na educação alinhados a um neoliberalismo da educação.

\section{Neonarcisificação na-da Educação}

O narcisismo das pequenas diferenças é a obsessão por diferenciar-se daquilo que resulta mais familiar e parecido.

- Sigmund Freud

Ao pensarmos a neoliberalização da educação e os neofundamentalismos na educação, partimos de uma figura dada: um indivíduo, ou sujeito neoliberal, compreendido e investido enquanto um empresário de si (Foucault, 2008; Dardot e Laval, 2016). Este individuo empresário de si é vislumbrado enquanto um Eu-empresário que atua em meio ao cenário contemporâneo, que se vislumbra-se na pós-modernidade. Todavia, este Eu-empresário é produzido, elaborado e formado enquanto tal - vide que a neoliberalizaçãoneofundamentalismo da-na educação investe para a formação deste sujeito -, ou seja, passa por um processo de narcisificação.

Evidenciamos em Sigmund Freud $(2011 ; 1996)$ que o narcisismo se encontra interligado aos processos de constituição do Eu. Este processo prescinde a existência de um Outro com o qual interajo e me reconhece enquanto sujeito na relação Eu-Outro-Nós. Este Outro é primariamente um outro externo em um narcisismo primário, dualizando-se ao passo que é internalizado e duplicado (é a isto que Freud tratou por Superego). A formação do Eu neste sentido encontra-se associado a delimitação entre o Eu e o Outro. O Eu, o Outro e o Nós, assim, só se sustenta enquanto uma relação de diferenciação-diversificação. A limitação do EuOutro-Nós depara-se com fronteiras que freiam o Eu e o demarcam, impedem que a expansão invada o que não é da instância do Eu, posiciona o que é do Eu e o que é do Outro. Esta demarcação é sustentada ao passo que as crenças, valores e saberes-verdades encontram suas referencias e critérios de validação-reconhecimento no encontro com a diferença-Outro.

Este encontro entre o Eu e o Outro para validação de si e dos saberes-verdades, no encontrar das diferenças, mantem-se em constante negociação, reflexão e diferenciação. A produção é compartilhada, e por ser de tal forma coloca os regimes de moralidade sob constante reinvenção. Ao passo que o saber-ação é refletido, ele incorre para o campo da ética, desmantelando a moralidade (Nietzsche, 2019). Este Eu-Outro que é produto das alteridades só é consubstancializado ao passo que as diferenças pulsam em dinâmicas re-criativas. Esta é a 
percepção que as teorizações (pós)críticas lançaram para pensar a educação sob o marco da diferença, as pedagogias-educações como espaço de alteridade-heterogeneidades-heterotopias.

Como apresentado o Programa EsP não se sustenta pela orientação de uma educação ética, mas sim pela óptica moral-religiosa dos pais-mercados. A propositiva é então uma outra dinâmica de narcisificação-subjetivação, autorreferenciada no neofundamentalismoneoliberalismo pregado a ser seguido: uma neonarcisificação. O neoliberalismo investe na ruptura com as fronteiras para ampliar a produção, sendo necessário desestruturar a noção do Outro da alteridade; o neofundamentalismo lança mão do medo e da (auto)vigília para arcabouçar o projeto neoliberal e manter as moralidades longe do alcance das críticas. Neste domínio noção de Eu é convertida na desregulamentação do Outro que lhe impunha limites: o Eu se expande a caminho de maior produção-desenvoltura-lucro, para tal inverte suas crenças, valores e saberes-verdades a um quadro de validação autossustentados e autocentralizados em si mesmo.

Este quadro de sustentação faz uso três mecanismos contemporâneos da narcifisicação na-da educação: i) recorre a apropriação da discursividade da pós-modernidade, ao passo que se tudo torna-se narrativa, para esses a própria narrativa é autovalidada em sua autrocentalidade e autossustentação (Lyotard, 2002); ii) opera o enquadre de um processo de superidentificação, de modo que o Outro é substituído por um Eu-no-Outro, o Outro se torna uma expansão do Eu e o Eu se torna uma expansão do Outro esfacelando as fronteiras (Freud, 2011) - os jogos de algoritmos, as associações guiadas pelo igual e pelo ideal de igual e a homogeneização é exercida por três movimentos (a) o Outro é um Eu por também ser um empresário de si guiado pelos valores do mercado, (b) o Outro é um Eu pois eu elimino do convívio qualquer sujeito que coloque a critica em operação, ou seja, a diferença em jogo, e (c) o Outro é um Eu pois também apoia e empreende pelo Programa Escola sem Partido em sua base neoliberal-neofundamentalista; esta neonarcisificação também se dá no iii) instalar de um retorno ao totemismo (Freud, 1996), em que o Outro é um Eu pois segue o mesmo totem e regimes de sacralidade - a educação não toca em valores morais-religiosos e na 'propriedade' dos pais, a educação não questiona a ordenação social e os sintomas-efeitos do neoliberalismo, a educação não suscita a diferença, a educação privatiza todos os valores e espaços sob a lógica do mercado... e estes mandamentos não serão tocados-profanados, são sacros.

Assim o Programa Escola sem Partido instaura uma (neo)narcisificação na-da educação, pelo investimento em discursividades-pedagogias-educações reativas as diferenças- 
diversificações. Multiplicando o Eu e as barbáries do igual presente aqui e totemizadas no porvir...

Nesta esteira de articulações do neoliberalismo da educação, do neofundamentalismo na educação e da (neo)narcificação na-da educação, perceptadas enquanto mecanismos de operação de uma pedagogia-educação reativa na contemporaneidade que se coloca (tomando o Progama EsP representação de tais projetos epistêmicos-sociais), deixamos a indagação com o intuito de deixar a referida diagnose em aberto: Como lidar com as educações e(m) barbáries que as reatividades tem suscitado frente as diferenças-diversidades? Como derivar o inferno do igual proposto e totemificado para reencontrar as diferenças? Como produzir outros possíveis?...

\section{Referências}

BRASIL. Constituição de 1988.

BRASIL. Projeto de Lei 246 de 2019 - institui o Programa Escola sem Partido.

CARVALHO, Fabiana Aparecida de; POLIZEL, Alexandre Luiz; MAIO, Eliane Rose. Uma escola sem partido: discursividade, currículos e movimentos sociais. Semina: Ciências Sociais e Humanas, Londrina, PR, v. 37, n. 2, p. 193- 210, 2016.

DARDOT, Pierre; LAVAL, Christian. A Nova Razão do Mundo: Ensaio sobre a sociedade neoliberal. São Paulo: Editora Boitempo, 2016

FOUCAULT, Michel. Microfísica do poder. Rio de Janeiro: Paz e Terra, 2016.

. Nascimento da biopolítica. São Paulo: Martins Fontes, 2008

. Tecnologias de si, 1982. Verve, v. 6, 2004, p. 321-360

FREUD, Sigmund. Psicologia das massas, análise do Eu e outros textos (1920-1923). São Paulo: Companhia das Letras, 2011

Imago, 1996

Totem e tabu e outros trabalhos - Volume XIII (1913-1914). Rio de Janeiro:

FURLAN, Cássia Cristina; CARVALHO, Fabiana Aparecida de. Comunismo e gênero no Escola sem Partido: notas para não sucumbir a uma pedagogia fascista. Revista FAEEBA Educação e contemporaneidade, v. 29, n. 58, 2020, p. 168-186

GALLO, Silvio. A Vila: microfascismos, fundamentalismo e educação. In: GALLO, Silvio; VEIGA-NETO, Alfredo (Orgs). Fundamentalismo \& Educação: A Vila. Belo Horizonte: Autêntica Editora, 2009, p. 17-36

GRAMSCI, Antonio. Cadernos do cárcere - v. I. Rio de Janeiro: Civilização Brasileira, 2006.

\begin{tabular}{|l|l|l|l|l|}
\hline Qovista Dialectus & Ano 10 & n. 22 & Edição Especial, junho 2021 & p. 175 - 195 \\
\hline
\end{tabular}


GUATTARI, Felix. As três ecologias. Campinas: Papirus, 2009

LIPOVETSKY, Gilles. A Era do Vazio. Barueri: Manole, 2005

LYOTARD, Jean-François. A condição pós-moderna. São Paulo: José Olympio, 2002.

NIETZSCHE, Friedrich. Genealogia da Moral: uma polêmica. São Paulo: Companhia das Letras, 2019

PENNA; Fernando de Araújo; SALLES, Diogo da Costa. A dupla certidão de nascimento do Escola sem Partido: analisando as referências intelectuais de uma retórica reacionária. In: MUNIZ, Altemar de Costa Arquivos; LEAL, Tito Barros (org.). Arquivos, documentos e ensino de história: desafios contemporâneos. Fortaleza: EdUECE, 2017. p. 13-38.

POLIZEL, Alexandre Luiz. Percepções do movimento escola sem partido: currículos pastorais e o professor enquanto catequista. Revista Amazônida, v.4, n.1, 2019a, p. 01-16

. É possível uma educação para as sexualidades em meio ao desejo 'cidadãos de bem'?. In: MAIO, Eliane; OLIVEIRA, Marcio de. (Orgs). Gênero, sexualidades e diferenças: categoria de análise, (des)territórios de disputa. Maringá: Eduem, 2019b, p 43-60

SILVA, Tomaz Tadeu da. Documentos de Identidade: uma introdução às teorias do currículo. Belo Horizonte: Autêntica, 2015.

SILVA, Vagner da Silva. O sujeito na vila: vontade de poder e ressentimento. In: GALLO, Silvio; VEIGA-NETO, Alfredo (Orgs). Fundamentalismo \& Educação: A Vila. Belo Horizonte: Autêntica Editora, 2009, p. 107-130

TIBURI, Marcia. Como conversar com um fascista. 5 ed. Rio de Janeiro: Record, 2016

VEIGA-NETO, Alfredo. Uma vila voltada para traz. In: GALLO, Silvio; VEIGA-NETO, Alfredo (Orgs). Fundamentalismo \& Educação: A Vila. Belo Horizonte: Autêntica Editora, 2009, p.67-106 